\title{
Some effects of ice crystals on the FSSP measurements in mixed phase clouds
}

\author{
G. Febvre ${ }^{1}$, J.-F. Gayet ${ }^{1}$, V. Shcherbakov ${ }^{1,2}$, C. Gourbeyre ${ }^{1}$, and O. Jourdan ${ }^{1}$ \\ ${ }^{1}$ Laboratoire de Météorologie Physique, UMR6016, CNRS/Université Blaise Pascal, Clermont-Ferrand, France \\ ${ }^{2}$ LaMP, Institut Universitaire de Technologie d'Allier, Montluçon, France
}

Correspondence to: G. Febvre (guy.febvre@opgc.univ-bpclermont.fr)

Received: 24 February 2012 - Published in Atmos. Chem. Phys. Discuss.: 20 March 2012

Revised: 6 September 2012 - Accepted: 11 September 2012 - Published: 1 October 2012

\begin{abstract}
In this paper, we show that in mixed phase clouds, the presence of ice crystals may induce wrong FSSP 100 measurements interpretation especially in terms of particle size and subsequent bulk parameters. The presence of ice crystals is generally revealed by a bimodal feature of the particle size distribution (PSD). The combined measurements of the FSSP-100 and the Polar Nephelometer give a coherent description of the effect of the ice crystals on the FSSP-100 response. The FSSP-100 particle size distributions are characterized by a bimodal shape with a second mode peaked between 25 and $35 \mu \mathrm{m}$ related to ice crystals. This feature is observed with the FSSP-100 at airspeed up to $200 \mathrm{~m} \mathrm{~s}^{-1}$ and with the FSSP-300 series. In order to assess the size calibration for clouds of ice crystals the response of the FSSP-100 probe has been numerically simulated using a light scattering model of randomly oriented hexagonal ice particles and assuming both smooth and rough crystal surfaces. The results suggest that the second mode, measured between $25 \mu \mathrm{m}$ and $35 \mu \mathrm{m}$, does not necessarily represent true size responses but corresponds to bigger aspherical ice particles. According to simulation results, the sizing understatement would be neglected in the rough case but would be significant with the smooth case. Qualitatively, the Polar Nephelometer phase function suggests that the rough case is the more suitable to describe real crystals. Quantitatively, however, it is difficult to conclude. A review is made to explore different hypotheses explaining the occurrence of the second mode. However, previous cloud in situ measurements suggest that the FSSP100 secondary mode, peaked in the range $25-35 \mu \mathrm{m}$, is likely to be due to the shattering of large ice crystals on the probe inlet. This finding is supported by the rather good relationship between the concentration of particles larger than $20 \mu \mathrm{m}$
\end{abstract}

(hypothesized to be ice shattered-fragments measured by the FSSP) and the concentration of (natural) ice particles (CPI data). In mixed cloud, a simple estimation of the number of ice crystals impacting the FSSP inlet shows that the ice crystal shattering effect is the main factor in observed ice production.

\section{Introduction}

The investigating of climate, radiative transfer or numerical forecast modelling require a good knowledge of the microphysical properties of clouds. In situ measurement science uses quantitative types of probes in order to perform particle size analyses of hydrometeor range going from a few microns to a millimetre or more. One such classic probe is the Forward Scattering Spectrometer Probes (FSSP), designed to count cloud droplets individually in different size ranges. Particle size is determined from measured light intensity using Mie scattering theory (Knollenberg, 1970, 1981). There are many applications where FSSP is used especially when droplet spectra are required. Cober et al. (1995, 1999), based on works of Ashenden and Marwitz (1998) and Miller et al. (1998), give the case of aircraft icing characterizations, as an example of FSSP use. Cober and Isaac (2012) highlighted the interest of FSSP for the measurements of the super large droplet characterisation. The LaMP's activities in the area of aircraft icing and the importance of the FSSP in these studies motivate exploration of any situation capable of increasing the knowledge of FSSP behaviour. The objective is to calculate bulk parameter such as liquid water content (LWC) and mean volume diameter (MVD) with minimum errors. 
The scientific community of cloud physics (see the recent review on cloud in situ instruments by Baumgardner et al., 2011) seems to agree that the FSSP is an accurate instrument for all water clouds, even if the discussion still open concerning the quantification of uncertainties in the evaluation of LWC. Nagel et al. (2007) showed, with a rigorous calibration method, that a sizing accuracy of about $10 \%$ can be expected.

The interpretation of measurements is quite complicated in the presence of ice particles. Gardiner and Hallett (1985) suggested that the FSSP gives a false response in ice clouds and should not be used for the characterization of small ice crystals. Since then Gayet et al. (1996) have compared the PMS cloud probe (2D-C) and FSSP size distributions in the poorly measured overlap region and have proposed that observations made with the FSSP probe can be considered reliable if the ice crystals are small and quasi-spherical. In such cases there is indeed good agreement between the 2D-C and FSSP. Ivanova et al. (2001) suggest, comparing the FSSP and the DRI Cloudscope spectra, that errors due to aspherical effects appear marginal when radiative properties are calculated. Mitchell et al. (1999) found similar good agreement when hexagonal plates were sampled, using the same experimental design.

Even if the sizing of ice crystals seems reliable with FSSP measurement in some particular situations (i.e. spherical particles, Gayet et al., 1996), the analysis of the size response should consider specific theoretical methods adapted for aspherical particles (see for instance Borrmann et al., 2000). In many situations, clouds with mixed phase (liquid water droplets and ice crystals) introduce risks for misinterpretation if differentiation between the two hydrometeor phases is not possible. As Riley (1998) states, the problem would not be important if mixed conditions were rare, but mixed phase clouds are a common situation. In his review, this author found that mixed-phase conditions in clouds were observed with a frequency of between $20 \%$ and $90 \%$, depending on the region, environment, and temperature.

Cober et al. (2001) present an interesting discussion about the responses of several common instruments in mixed-phase situations. They conclude that it is difficult to evaluate the contribution of each phase to a measurement. In the case of the FSSP, the presence of ice particles could lead to a wrong evaluation of cloud parameters such as liquid water content (LWC) and mean volume diameter (MVD).

Moreover, it is extremely important to consider the effect of ice crystal shattering induced errors when analysing data, depending on the type and version of probe used. Jensen et al. (2009) have shown that measurements with CAS in clouds with large crystals present contain large errors due to crystal shattering. Korolev et al. (2011) have shown that the response of the FSSP-100 in ice clouds can be almost entirely due to ice crystal shattering on the inlet tube, and this can be almost greatly eliminated by removing the sample tube, and using deflecting probe tips.
In this context, this paper is a contribution to the interpretation of the effects of ice particles on FSSP measurements using a data set for Arctic mixed phase clouds. The data discussed were obtained during the ASTAR 2007 (Arctic Study on Tropospheric Aerosol and Radiation, Engvall et al., 2008) and POLARCAT (Polar Study using Aircraft, Remote Sensing, Surface Measurements and Models, of Climate, Chemistry, Aerosols, and Transport, Law et al., 2008) field experiments. During ASTAR, the cloud observations were carried out onboard the Polar2 (Do228) operated by AWI (Alfred Wegener Institute for Polar and Marine Research) whereas the ATR42 research aircraft operated by SAFIRE (Service des Avions Français Instrumentés pour la Recherche en Environnement) was used during POLARCAT. A combination of cloud in situ instruments was installed on both aircraft, namely: a standard Forward Scattering Spectrometer Probe (FSSP-100), a Polar Nephelometer (Gayet et al., 1997), as well as a Cloud Particle Imager (CPI, Lawson et al., 2001), to measure cloud particle properties in terms of scattering, morphology and size, and in-cloud partitioning of ice/water content. Standard 2D-C, 2D-P instruments as well as liquid water devices (i.e. King probe, Nevzorov and PVM-100) were used in addition to the ATR42 in situ cloud instrumentation.

A short description of the instruments and the analysis of cloud situations are first presented in Sect. 2. Then the paper describes in detail the FSSP response in the presence of ice particles (Sect. 3). A presentation of the microphysical and optical properties of a mixed-phase boundary-layer cloud observed during the 8 April 2007 situation (ASTAR) will then be given. The interpretation of the measurements from independent techniques leads to a clear identification of the effects of ice crystals on FSSP particle size distributions. This feature is confirmed with additional data obtained during POLARCAT, studied in order to experience a wide range of ice crystal conditions. Section 4 discusses the implications on FSSP measurements and Sect. 5 attempts to explore different causes explaining the second mode presence when ice crystals are present in clouds. The shattering ice crystal effect is then discussed.

\section{Instrumentation and cloud situations}

The cloud instrumentation installed onboard the Polar2 and ATR42 aircraft has been thoroughly described by Gayet et al. (2009). The instrumentation package includes three independent techniques for the description of particles within a diameter range varying from a few micrometers (typically $0.3 \mu \mathrm{m}$ ) to about $2 \mathrm{~mm}$ : (1) the PMS FSSP-100 probe and PMS-FSSP-300 probe, (2) the Cloud Particle Imager (CPI) and (3) the Polar Nephelometer. Accuracy of measurements may be compromised by ice particle impacts on surfaces upstream of the sample areas (FSSP, CPI, Polar Nephelometer, 2D-C, ... for instance, see among others Gardiner and Hallett (1985), Field et al. (2003), Korolev et al. (2005), 
Heymsfield (2007), Jensen et al. (2009). The new generation of cloud instruments (e.g. CDP, 2DS) are being equipped with innovative arms and leading edge tips especially designed to reduce the shattering effects (Korolev et al., 2011) and provide inter-arrival time information to further help separate real and artefact-shattered particles (Field et al., 2003, 2006; Lawson, 2011).

As these instruments were unavailable for the present study, the possible effects of resulting ice-crystal shattering will be discussed together with the results below.

The FSSP instruments provide information on droplet size distribution for the size range of $0.3-20 \mu \mathrm{m}$ for 300 version (Baumgardner et al., 1992), 2-47 $\mu \mathrm{m}$ for standard 100 version (Baumgardner et al., 2002) and of 6 to $90 \mu \mathrm{m}$ for the extended range 100 version. For water droplet clouds, the accuracy of the derived effective diameter and liquid water content has been estimated as $2 \mu \mathrm{m}$ and $30 \%$, respectively. Referring to the effects of ice crystal shattering on FSSP data, the bulk parameters could be overestimated by about 15-20\% (Heymsfield, 2007) and the particle concentration by a factor of 2 or 3 (Field et al., 2003) or in more extreme situations by 2 orders of magnitude, as is shown in the recent work of Korolev et al. (2011). Similar measurement uncertainties due to shattering effects are expected for CPI data (see below).

The CPI registers cloud-particle images on a solid-state, one-million pixel digital charge-coupled device (CCD) camera by freezing the motion of the particle using a $40 \mathrm{~ns}$ pulsed, high-power laser diode (Lawson et al., 2001). A particle detection system with upstream lasers defines the focal plane so that at least one particle in the image is in focus. Each pixel in the CCD camera array has an equivalent size in the sample area of $2.3 \mu \mathrm{m}$, so particles of sizes ranging from approximately $10 \mu \mathrm{m}$ to $2 \mathrm{~mm}$ are imaged. In a previous paper (Gayet et al., 2009), conclusive comparisons between CPI and PMS 2D-C/2D-P particle size distributions during POLARCAT were shown. These results validate the CPI calibration as well as the data processing method and suggest that the errors on the size distributions and derived microphysical parameters calculated from the (calibrated) CPI are of the same order as those from the PMS instruments.

The Polar Nephelometer (Gayet et al., 1997) measures the scattering phase function of an ensemble of cloud particles (i.e. water droplets or ice crystals or a mixture of these particles ranging in size from a few micrometers to about $1 \mathrm{~mm}$ in diameter). Direct measurement of the scattering phase function allows the discrimination of particle shapes (spherical liquid water droplets or aspherical ice crystals) and the calculation of integrated optical parameters (such as extinction coefficient and asymmetry parameter $(g)$, see Gayet et al., 2002).

Indeed, Sassen and Liou (1979) propose an identification of cloud phase on the basis of their side scattering differences with water or ice particles. The phase function measured from Polar Nephelometer (PN) could be used to sep- arate the phase of hydrometeor. Crépel et al. (1997) present a method of liquid or ice discrimination based on the comparison of scattered power from two different side angles: $113^{\circ}$ and $141^{\circ}$ (rainbow peak). By using a shape criterion of the phase function as the asymmetry factor, discrimination between water droplets or ice crystals is possible. Zhang et al. (2007) show different theoretical values of $g$ ranging from 0.87 for ice spheres to 0.6 for polyhedrons at a wavelength of $0.66 \mu \mathrm{m}$. Gayet et al. (2002) show that results from PN measurements indicate g-values ranging from 0.86 to 0.75 for water droplets and ice crystals respectively; this result is in good agreement with those obtained by Garrett et al. (2001).

In this study, the PN phase function shape (through the asymmetry parameter) will be used in order to discriminate the phase of the cloud particles. The accuracies of the extinction coefficient and asymmetry parameter derived from the Polar Nephelometer are estimated to be within $25 \%$ and \pm 0.05 , respectively (Jourdan et al., 2010). These measurement uncertainties could be adversely affected by ice-crystal shattering on the probe inlet (Shcherbakov et al., 2010).

The situations presented below all address Arctic boundary layer mixed-phase stratiform clouds. They exhibit a cloud top layer dominated by liquid-water in which ice precipitation was present. This is a common feature observed in such clouds (McFarqhar et al., 2007) even for cloud top temperatures down to $-25^{\circ} \mathrm{C}$ during ASTAR and POLARCAT. Generally, very efficient ice growth processes are expected in boundary layer clouds since appreciable liquid water is converted into ice water with large precipitating ice crystals. During ASTAR, the flights were carried out over the Greenland Sea in the vicinity of the west coast of the Svalbard Archipelago whereas the POLARCAT flights were conducted over the Greenland Sea towards Northern parts of the Scandinavian Peninsula.

\section{Evidence of the FSSP response to ice crystals}

\subsection{The problems of ice crystal detection}

The sizing principle of the FSSP is based on the measurement of scattered light between $3^{\circ}$ and $12^{\circ}$ by a single particle (Dye and Baumgardner 1984; Field et al., 2003). Indeed, for spherical particles, Mie theory gives a relation between scattered energy and particle size. Based on such calculations, the measured intensities are interpreted as particle sizes by the probe electronics (Pinnick et al., 1981). As a consequence, for nominal hydrometeor sizing, the calibration curve (i.e. the relationship between measured scattered intensities and sizes) of the FSSP is extremely important. Mie calculations assume liquid water spheres. Particles with aspherical shape could present significant differences in scattering properties, especially in terms of scattering light energy as a function of scattering angle. In others words, the phase function (angular distribution of diffuse energy) is sensitive to the 


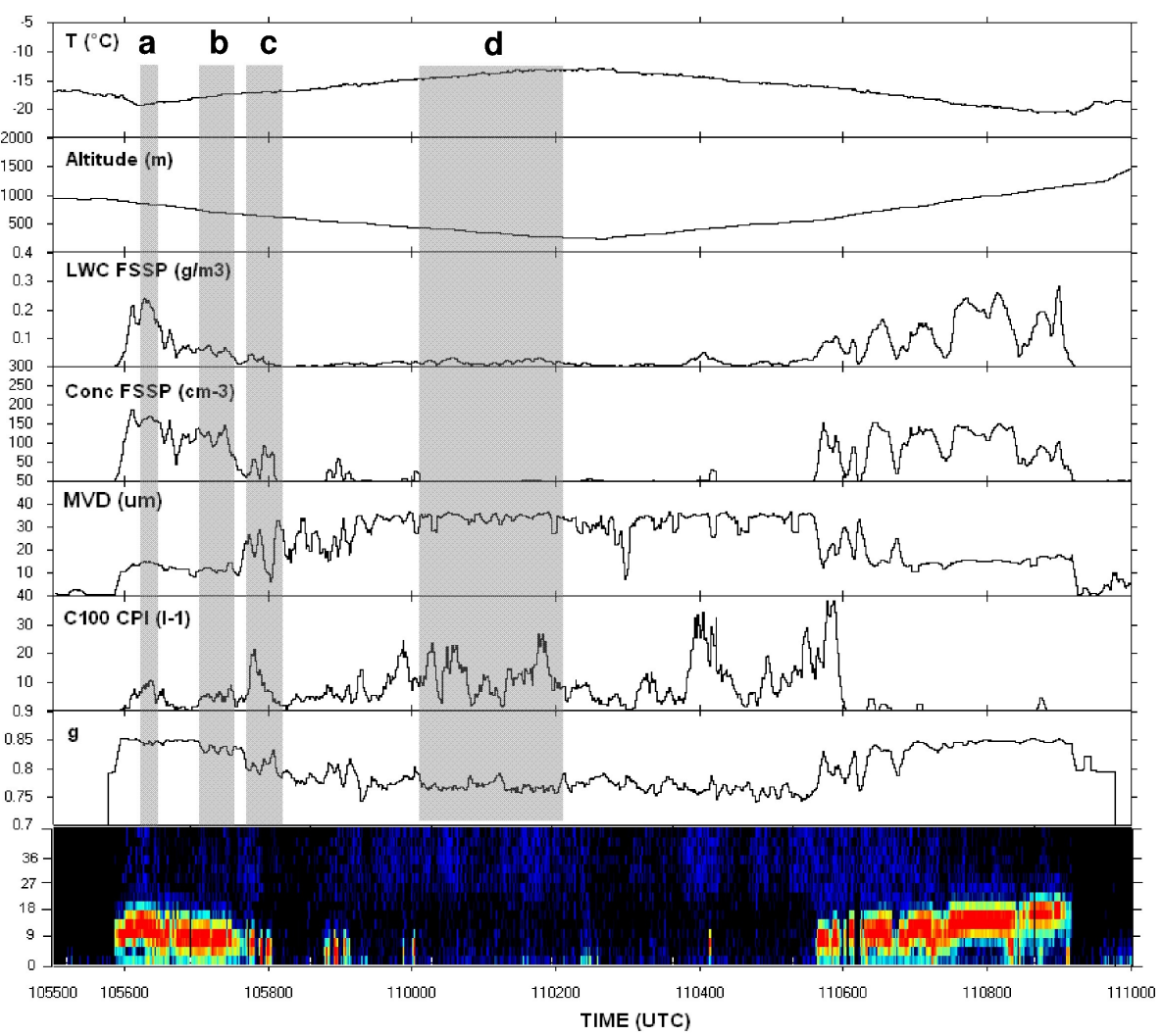

Fig. 1. Time-series of cloud parameters measured during a descent-climbing sequence in the mixed-phase stratiform cloud layer (ASTAR, 8 April 2007 case study). The parameters (plotted at $1 \mathrm{~Hz}$ ) are the following: the air temperature, altitude, liquid water content (LWC), droplet concentration and mean volume diameter (MVD), the concentration of ice particles larger than $100 \mu \mathrm{m}(C 100)$, the asymmetry parameter $(g)$ and the FSSP size distribution represented with colour-scaled to the particle concentration.

morphological characteristics of the illuminated particle (see for instance examples of Polar Nephelometer measurements, Gayet et al., 1998). For the same geometric volume, light scattered by aspherical particles between 3 and 12 degrees differ from that predicted by Lorentz-Mie theory (Borrmann et al., 2000). Thus, instrument sizing can be affected, leading to uncertainties in the bulk parameter calculation (e.g. mean diameter, MVD, LWC, etc.).

In order to minimize uncertainties, several techniques combining different instruments used. For example Niu et al. (2008) used Icing Rosemount probe data in order to define a threshold for removing the noise due to ice contamination of the FSSP data. This approach is possibly effective in mixed cloud conditions to isolate liquid water zones, but reliable measurements are lost in the presence of a high concentration of ice crystals.

To resume, during FSSP measurement analysis, the presence of ice crystals can induce a wrong interpretation if the used scattering model of the particles is not appropriate. In these conditions, when the FSSP is the only in-situ measurement probe, the interpretation in mixed and ice cloud is unsafe.
Conversely, as Gardiner and Hallett (1985) have claimed, the shape of the spectra in the presence of ice particles may be a good indication of the presence of ice crystals. In this study, we will demonstrate below that the bimodal spectrum is undoubtedly the signature of ice crystals.

Our observation concerning the bimodal particle size distribution (PSD) feature in the presence of ice crystals has been previously noted without a specific interpretation (Lawson, 2011; Ivanova et al., 2004).

\subsection{The case study of the 8 April 2007 (ASTAR)}

Figure 1 displays the time-series of cloud parameters measured during a descent-climbing sequence in the mixedphase stratiform cloud layer and yielded precipitations (8 April 2007 case study, ASTAR 2007 experiment). The parameters (plotted at $1 \mathrm{~Hz}$, i.e. $70 \mathrm{~m}$ horizontal resolution) are the following: the air temperature, altitude, liquid water content (LWC), droplet concentration and mean volume diameter (MVD) inferred from FSSP-100, the concentration of ice particles larger than $100 \mu \mathrm{m}(C 100$ from the $\mathrm{CPI})$, the asymmetry parameter ( $g$ from the Polar Nephelometer) and finally the FSSP size distribution represented by a coloured scale of 


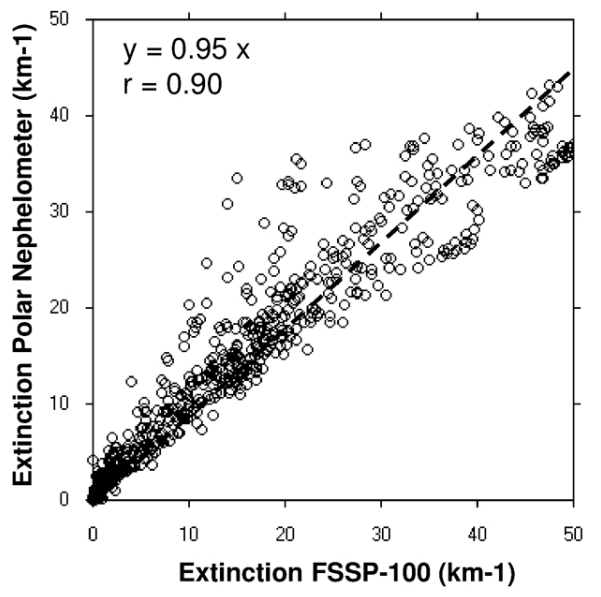

Fig. 2. Relationship between the extinction measurements from the Polar Nephelometer and the FSSP-100. The data correspond to cloud liquid water only (i.e. $g>0.83$ ). ASTAR, 8 April 2007 case study.

the particle concentration. The consistency of the FSSP and PN data was determined by comparing extinction estimates from both probes in cloud sections thought to be dominated by liquid (i.e. $g>0.83$ ). The results displayed on Fig. 2 show that the slope parameter $(0.95)$ is close to a perfect agreement and the dispersion of the data points (20\%) is within the probe uncertainties. The descent-climbing sequence provides the vertical profiles of LWC, MVD, $g$ and $C 100$ as displayed on the four panels on Fig. 3. The results show that liquid water droplets dominate the cloud microphysical and optical properties in the upper parts of the cloud from $600 \mathrm{~m} /-16^{\circ} \mathrm{C}$ to $1200 \mathrm{~m} /-20^{\circ} \mathrm{C}$ (LWC up to $0.3 \mathrm{~g} \mathrm{~m}^{-3}$ ) as confirmed by the asymmetry parameter values ranging from 0.830 and 0.855 . The $C 100$ profile indicates that ice particles are found even near the cloud top with rather a low concentration $\left(\sim 51^{-1}\right)$, which then increases significantly (up to $\sim 401^{-1}$ ) at lower levels, with g-values of about 0.77 . Indeed, most of the particles bigger than $100 \mu \mathrm{m}(C 100)$ are identified as ice particles from the CPI imagery.

\subsection{Evidence of the FSSP response to ice crystals}

In order to reveal the FSSP response to ice crystals we have selected four time-sequences which are marked on the timeseries on Fig. 1 by shadowed areas. Sequence (a) corresponds to the top of the cloud layer where mostly liquid water droplets are detected. Sequences (b) and (c) correspond to mixed-phase conditions (water droplets and ice crystals) and the last sequence (d) corresponds to precipitating ice crystals only. In order to achieve the statistical representativeness of the results, the length of the flight paths have been chosen according to particle concentration, i.e. by considering averages over $10 \mathrm{~s}$. for the first sequence, $20 \mathrm{~s}$. in mixed-phase conditions and $120 \mathrm{~s}$. for the bottom part with a very low
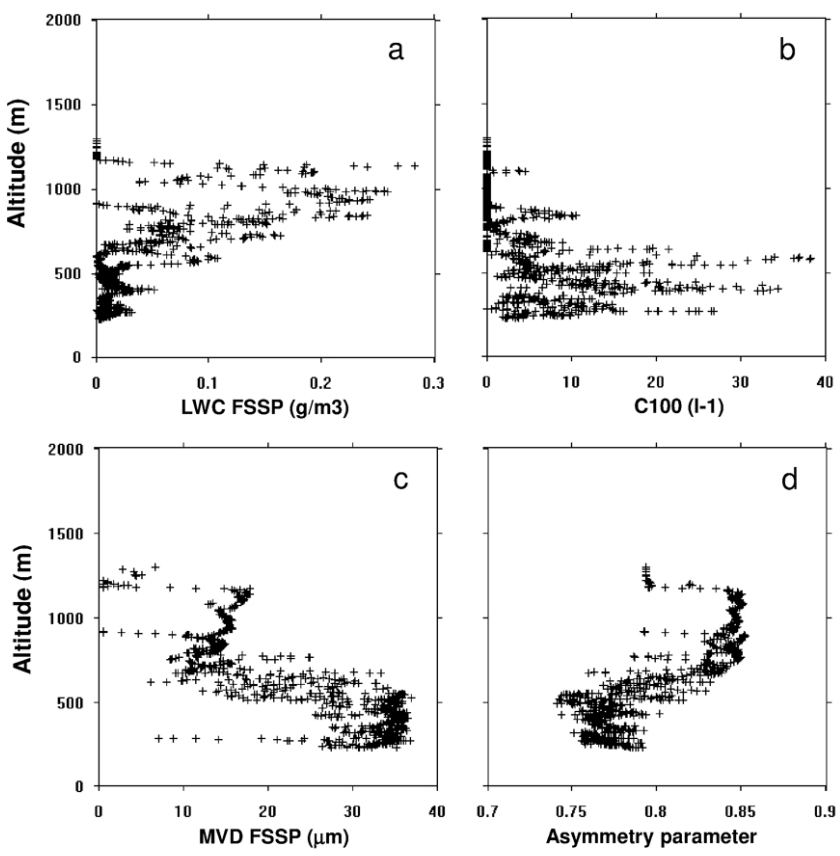

Fig. 3. Vertical profiles of cloud parameters obtained during the descent-climbing sequence on Fig. 1. (a): Liquid water content; (b): Concentration of ice particles with $d>100 \mu \mathrm{m}$; (c): Mean volume diameter and (d): Asymmetry parameter.

concentration. Table 1 summarises the corresponding main values of the microphysical and optical parameters with temperatures and altitudes.

Figure 4 (left panels) displays the mean particle size distribution (PSD) from FSSP and CPI measurements with some examples of ice crystal images for these four selected cloud sequences. The right panels of Fig. 4 represent the corresponding measured scattering phase function from the Polar Nephelometer (red dot symbols on the right panel). The theoretical phase function is calculated from the FSSP data using Mie theory (spherical water droplets) and plotted using black cross symbols. The close agreement between the PN measured and the theoretical FSSP-100 phase functions confirms the statement that this cloud is dominated by water droplets, as reported by Gayet et al. (2009) concerning this type of clouds. Nevertheless, the presence of some ice crystals is noted. Figure $4 \mathrm{~b}$ and $\mathrm{c}$, which correspond to mixed phase cloud, show that the FSSP particle size distributions exhibit a bimodal shape with a second mode peaked near $30 \mu \mathrm{m}$.

We propose to define the parameter REX as the ratio of extinction due to ice particles alone (CPI data) to the total extinction (water droplets and ice crystals from PN measurements). The REX values are reported in Table 1 for the four considered cloud sequences. The results on Fig. 4 and Table 1 show that the relative amplitude of the FSSP second mode increases with the REX values. In order to characterize the 
Table 1. Mean values of the cloud parameters over the times-sequences labelled a to $\mathrm{d}$ on Fig. 1. The parameters are the temperature, the liquid water content, the mean volume diameter, the asymmetry parameter, the second mode on total extinction calculated with FSSP PSD, the CPI on PN extinctions ratio (REX) and the concentration of ice particles (with $d>100 \mu \mathrm{m}$ ).

\begin{tabular}{lrrrcrrr}
\hline Sequence & $\begin{array}{r}T \\
\left({ }^{\circ} \mathrm{C}\right)\end{array}$ & $\begin{array}{r}\text { LWC } \\
\left(\mathrm{g} \mathrm{m}^{-3}\right)\end{array}$ & $\begin{array}{r}\text { MVD } \\
(\mu \mathrm{m})\end{array}$ & $g$ & Ext $_{\text {sm }} /$ Ext $_{\text {total }}$ & $\begin{array}{r}\text { REX ratio } \\
(\text { Ext CPI/Ext NP) }\end{array}$ & $\begin{array}{r}C 100 \\
\left(1^{-1}\right)\end{array}$ \\
\hline $\mathrm{a}$ & -19.2 & 0.23 & 14.7 & 0.843 & 0.007 & 0.03 & 8.9 \\
$\mathrm{~b}$ & -17.4 & 0.04 & 13.6 & 0.828 & 0.035 & 0.10 & 4.9 \\
$\mathrm{c}$ & -17.1 & 0.03 & 19.0 & 0.803 & 0.36 & 0.36 & 12.9 \\
$\mathrm{~d}$ & -14.0 & 0.02 & 33.7 & 0.769 & 0.91 & 0.80 & 12.1 \\
\hline
\end{tabular}
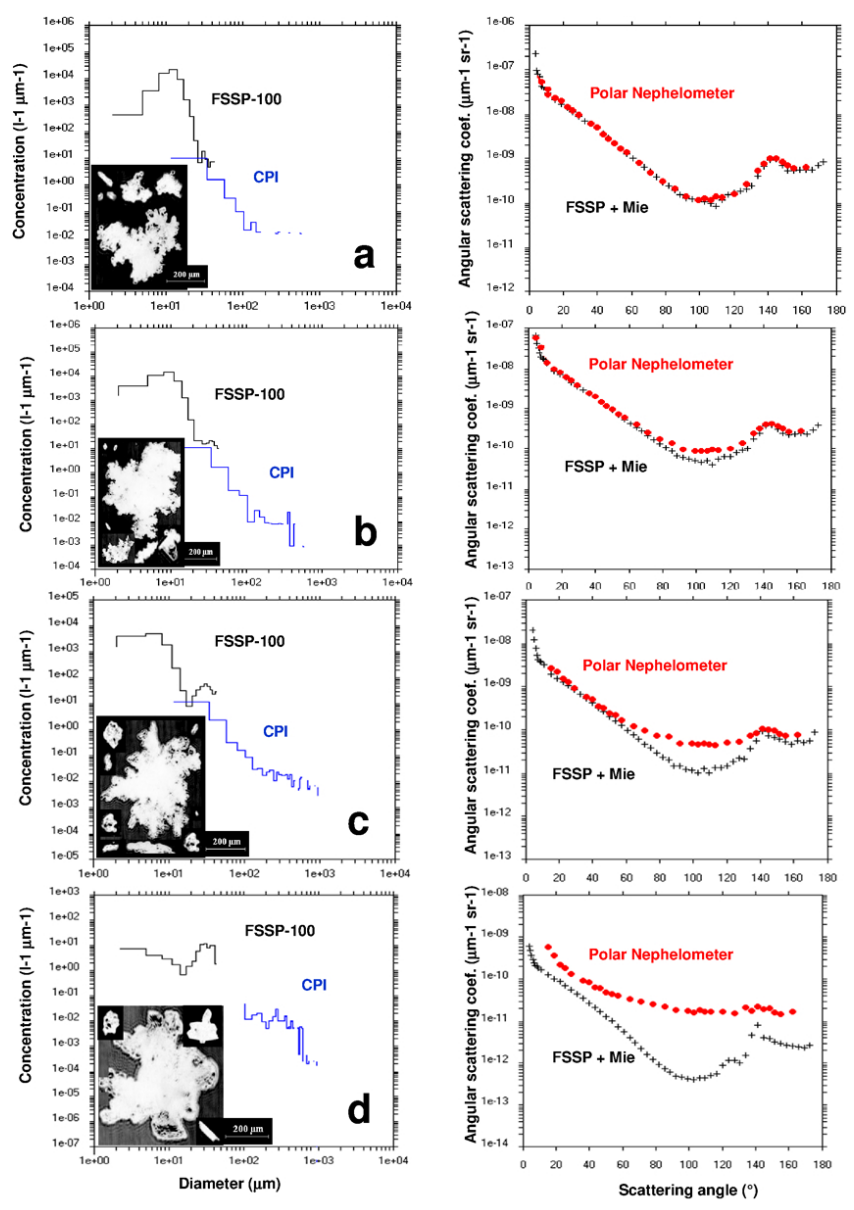

Fig. 4. Results obtained for the four cloud sequences labelled a, b, $c$ and d on Fig. 1. Left panels: Mean particle size distributions from FSSP and CPI measurements with examples of ice crystal images. Right panels: Mean measured scattering phase function (Polar Nephelometer with red dots symbols). The theoretical phase functions are calculated from the FSSP data with the Mie theory and plotted with black cross symbols.

FSSP second mode, we calculate the extinction coefficient from the FSSP-PSD (Ext $\left.{ }_{\text {total }}\right)$ and the fraction of this coefficient calculated over the second mode size range $\left(\mathrm{Ext}_{\mathrm{sm}}\right)$, i.e. for diameter bigger than $24 \mu \mathrm{m}$. We assume these particles to be spherical for the extinction calculation. Thus, the ratio between these two values $\left(\mathrm{Ext}_{\mathrm{sm}} / \mathrm{Ext}_{\text {total }}\right)$ gives the contribution of the second mode to the total extinction coefficient. These values are reported in Table 1. REX increases from 0.03 to 0.80 when $\mathrm{Ext}_{\mathrm{sm}} / \mathrm{Ext}_{\text {total }}$ increases from 0.007 to 0.91 . Furthermore, the differences between measured and theoretical phase functions increase with the magnitude of the second mode (see Fig. 4). These differences are the largest for PN sideward scattering angles.

This feature undoubtedly reveals the occurrence of aspherical particles with highly irregular shapes as exemplified on Fig. $4 \mathrm{~b}$ and c. In the precipitating ice particle zone (Fig. $4 \mathrm{~d}$ ), the second mode of the PSD has a strong identifying feature, and simulated and measured phase functions are no longer comparable.

To summarize, the combined measurements of the FSSP and Polar Nephelometer give a coherent description of the effect of the ice crystals on the FSSP response. The second FSSP mode in the range $25-35 \mu \mathrm{m}$ is undoubtedly a signature of ice crystals, which is more marked as the ice crystals increasingly dominate the cloud extinction properties. This feature seems to be a recurrent observation (Gardiner et al., 1985; Cober et al., 1995; Crépel et al., 1997). More recently such typical size spectra have also been reported by Gayet et al. (2009, see their Fig. 4b).

In order to generalise these observations, the combined data sets in mixed-phase clouds from ASTAR 2007 and POLARCAT experiments have been used. During these two experiments, both the FSSP and Polar Nephelometer data were processed over $1 \mathrm{~Hz}$ frequency and represent about 30000 available measurements. Two parameters have been defined to characterize the second mode of the particle size distribution and the scattering phase function, i.e. the mean volume diameter (from the FSSP) and the asymmetry parameter (PN data). Figure 5 displays the $g$-MVD scatter plots of the 30000 measurements. The results show that two main domains (labelled A and B) can be identified and are representative of two different cloud properties. Domain A, with MVD and $g$ centered on $35 \mu \mathrm{m}$ and 0.78 , respectively, represents a typical ice particle population, whereas domain $\mathrm{B}$ (MVD and $g$ centred on $10 \mu \mathrm{m}$ and 0.84 ) is related to typical liquid water droplet clouds. We note on Fig. 5 that only 


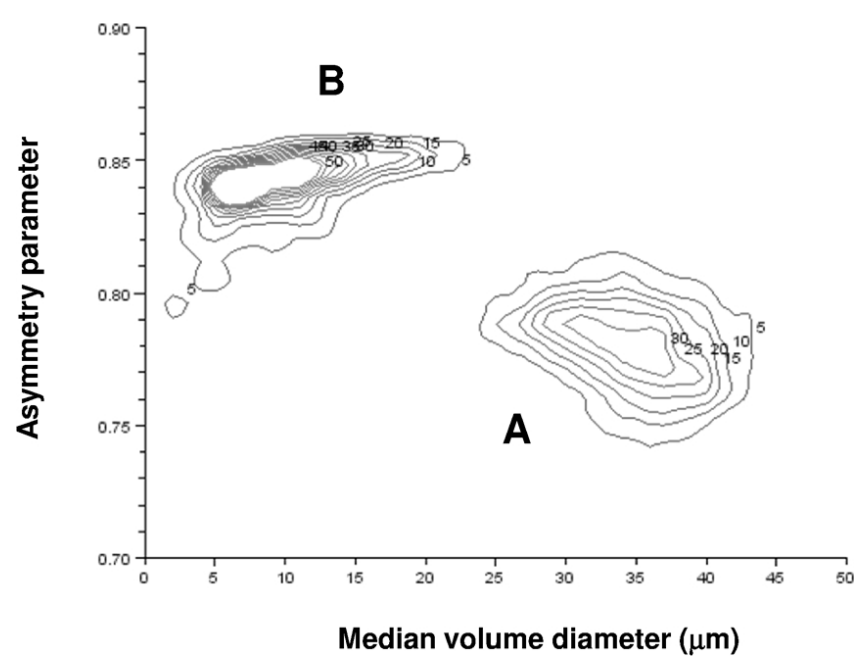

Fig. 5. Mean volume diameter-asymmetry scatter plots of the FSSP-100 and Polar Nephelometer measurements obtained in mixed-phase clouds during ASTAR and POLARCAT experiments ( $\sim 30000$ data). The number of observations are represented by isolines.

a few data points are observed between the two main domains A and B. This feature is typical of Arctic mixed-phase clouds. Indeed, this confirms that these clouds have the liquid fraction $(f l$, i.e. the ratio of liquid water on the total water: liquid + ice) $f l<0.2$ or $f l>0.8$, with very few values in between (i.e. clouds were either dominated by liquid or ice, but few clouds had relatively equal contributions of ice and water) as following observed by Cober et al. (2001), Korolev et al. (2003) and MacFarquhar et al. (2007). The next section will discuss the implications of the presence of ice particles on FSSP measurements

\section{Implications on FSSP measurements in mixed-phase and ice clouds}

Our results clearly show that the second mode in the range $20-35 \mu \mathrm{m}$ of the FSSP-100 size distribution is associated with the presence of ice particles. It should be noted that a similar feature is observed with the FSSP-300 instrument. Indeed, Fig. 6a displays particle size distributions simultaneously measured in a stratiform mixed-phase cloud by both FSSP series 100 and 300 on the ATR42 aircraft (POLARCAT Summer experiment). The results above have been obtained from airborne measurements performed by twin-engine aircraft (Do228 and ATR42) with airspeed ranging from 80 to $100 \mathrm{~m} \mathrm{~s}^{-1}$. It should be highlighted that a similar feature has already been obtained with the same FSSP-100 instrument but with higher airspeed $\left(\sim 200 \mathrm{~m} \mathrm{~s}^{-1}\right)$ onboard the DLR Falcon during the AEROCONTRAIL experiment (Gayet et al., 1998). Figure 6b displays typical FSSP size distributions measured during ASTAR and AEROCONTRAIL experiments showing a different second mode as a function of the
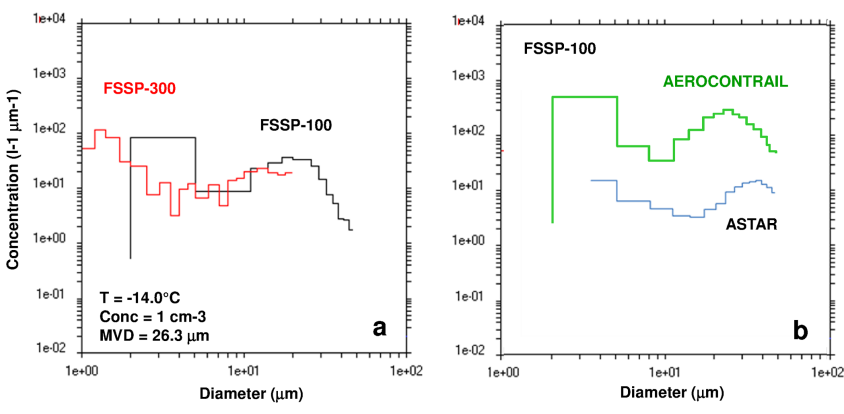

Fig. 6. (a): Composite representation of the particle size distributions measured simultaneously by the FSSP-100 and the FSSP300 in mixed phase clouds during the POLARCAT experiment (12 July 2008). (b): Composite representation of the particle size distributions measured by the FSSP-100 during ASTAR with an airspeed of $100 \mathrm{~m} \mathrm{~s}^{-1}$ and during AEROCONTRAIL with an airspeed of $200 \mathrm{~m} \mathrm{~s}^{-1}$.

airspeed $\left(25 \mu \mathrm{m}\right.$ at $200 \mathrm{~m} \mathrm{~s}^{-1}$ against $35 \mu \mathrm{m}$ at $\left.100 \mathrm{~m} \mathrm{~s}^{-1}\right)$. Lawson (2011) also reported a secondary mode on FSSP measurements carried out at high airspeed $\left(\sim 200 \mathrm{~m} \mathrm{~s}^{-1}\right.$ with the DC8 NASA aircraft) in cirrus clouds (see his Fig. 10). Therefore a common feature is observed in the presence of ice crystals regardless of the probe version (with sample inlet) and airspeed. Recent results of Korolev et al. (2011) suggest that behaviour would be radically different without the sample inlet, as is discussed below in Sect. 5 .

It is difficult to give a satisfactory interpretation of this particular shape of the FSSP dimensional spectra. Gardiner and Hallett (1985) concluded that the mechanism for the response of the FSSP to ice particles is not well understood. A more critical aspect that could be considered is the probe size response to aspherical particles. Theoretically, the interpretation of FSSP measurements draws on the knowledge of the scattering phase function of sampled particles. Indeed, although modelling and measurement means are the norm, the use of only one aspherical particle randomly oriented in the laser beam is rarely considered and is thus poorly documented. Shcherbakov et al. (2006) showed a good agreement between phase function measurements and modeling of a single ice particle from observations carried out during the South Pole Ice Crystal Experiment. The model was designed in order to take into account the particle orientation in the laser beam.

Considering the modeling of an ensemble of ice crystals, FSSP-300 size bins were defined from T-matrix calculations by Borrmann et al. (2000) assuming randomly oriented aspherical (i.e. rotationally symmetric ellipsoid) particles with an aspect ratio of $1: 2$. The upper size limits were found to be $18.0 \mu \mathrm{m}$ and $16.1 \mu \mathrm{m}$ for ice spheres and aspherical ice particles, respectively (Gayet et al., 2012). A closure method was used in order to validate the proposed FSSP-300 size calibration by comparing the extinction coefficients derived from the Polar Nephelometer and the FSSP-300. 
In the next section we propose a theoretical FSSP-100 size calibration for ice crystals assuming hexagonal particles.

\subsection{Theoretical FSSP-100 size calibration to ice crystals}

In order to assess size calibration for clouds of ice crystals, the response of the FSSP-100 probe with forward scattering aperture from $3^{\circ}$ to $12^{\circ}$ was numerically simulated using a light scattering model of randomly oriented hexagonal ice particles. More specifically, we employed the improved geometrical optics method (IGOM) developed by Yang and Liou $(1996,1998)$. The IGOM uses the ray-tracing technique to solve the near field on the ice crystal surface, which is then transformed to the far field on the basis of the electromagnetic equivalence theorem. Accordingly, the method can be applied to the computation of the extinction cross section for ice crystals with size parameters along the minimum dimension as small as $\sim 6$, and of the phase function when size parameters along the minimum dimension are larger than $\sim 20$ (Yang and Liou, 1996), meaning about $1.2 \mu \mathrm{m}$ and $4 \mu \mathrm{m}$, respectively, for the FSSP wavelength of $632.8 \mathrm{~nm}$. Basically, surface roughness is treated by assuming that a particle surface is composed of small facets that can be randomly tilted, and subsequently sampled according to different scenarios where the amount of tilt follows a Gaussian distribution (Yang and Liou, 1998).

We performed simulations for the roughness scale parameter $\sigma=0$ and $\sigma=0.2$. Surface roughness tends to smooth out peaks and peculiarities, leading to smoother phase functions. Indeed the signature of a particle shape is less visible on phase function when the particles are rough. These two $\sigma$ chosen values give, firstly, crystals with perfect plane surfaces and secondly, crystals with very deep rough surfaces. We can expect to span the complete domain of the roughness influence.

The responses of the FSSP-100 probe, i.e. scattering crosssections viewed by the probe, were computed considering forward scattering between 3 to $12^{\circ}$ with a refractive in$\operatorname{dex} m=1.3084+i 1.09 .10^{-08}$ of ice at the wavelength $\lambda=$ 0.6328 microns (Warren and Brandt, 2008) for hexagonal ice crystals having an aspect ratio of 0.5 and 2.0, namely, plates and columns.

The response presented here is the resulting scattering cross-sections as a function of the surface equivalent diameter in accordance with Mishchenko et al. (1997) when wavelength is small compared to particle size.

The resulting scattering cross-sections as a function of the surface equivalent diameter with Mie theory calculations (for spherical particles of the water refractive index) are represented on Fig. 7. As for the FSSP-100 results (Fugal and Shaw, 2009), with identical measured cross-sections, the surface equivalent diameters for smooth hexagonal ice crystals are twice as big as the corresponding water droplet diameters. In the case of rough crystals, the difference between water and ice is very small. With identical measured cross-

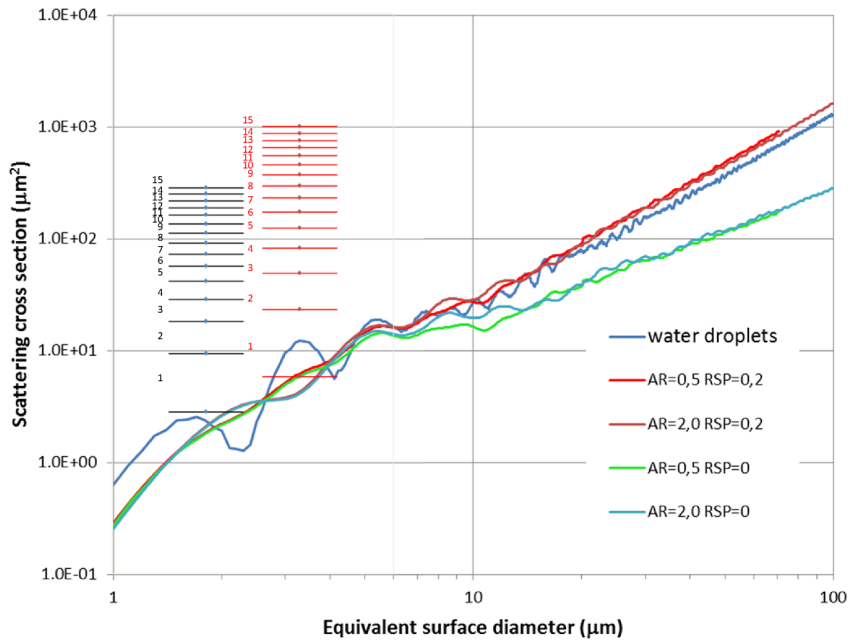

Fig. 7. The scattering cross sections for the FSSP-100 according to particle size obtained from hexagonal ice particle (aspect ratio (AR) of 0.5 and 2, roughness scale parameter (RSP) of 0 and 0.2 ). Calculations were done by averaging out over all orientations. The Mie theory calculations for water droplets are also reported. Both curves are for HeNe laser light $(\lambda=632.8 \mathrm{~nm})$ and the FSSP-100 scattering geometry $\left(3^{\circ}-12^{\circ}\right)$. The thin scales represent scattering cross sections for the 15 size classes of standard FSSP (black) and an extended range version (red). Values used to define the bin limit sizes (see Table 2).

sections, the surface equivalent diameters for rough hexagonal ice crystals are smaller than the corresponding water droplet diameters.

Therefore, considering the nominal calibration for water droplets, the size response for hexagonal ice crystals can be derived. In a similar way to Baumgardner et al. (1992) and Borrmann et al. (2000) the bin limit sizes of the FSSP-100 are given in Table 2 considering both standard size range (3$45 \mu \mathrm{m})$ and extended range $(6-90 \mu \mathrm{m})$ and considering both types of ice crystal, smooth and rough. Of course the results above could only be considered as an approximation of the size response of the FSSP-100 to irregular ice crystals such as those observed in mixed-phase clouds. Nevertheless, a theoretical sensitivity study with different particle aspect ratios ranging from 0.5 to 2.0 shows that the subsequent effects on the theoretical results are, on average, no larger than $15 \%$. Crystal roughness seems to play the crucial role in scattering properties. The difference between the water and smooth ice crystal size calibration is extremely large with an influence on channel width (see Table 2). For example, the mean sizes and channel widths of the last FSSP channel are $45 \mu \mathrm{m}$ vs. $103.1 \mu \mathrm{m}$ and $3 \mu \mathrm{m}$ vs. $8.5 \mu \mathrm{m}$ according to water droplet and smooth ice crystal size calibrations, respectively. On the contrary, the scattering properties of a crystal with a deep roughness are very close to the spherical model.

Coming back to the observations in mixed-phase clouds we may suggest that the second mode, peaked between $25 \mu \mathrm{m}$ 
Table 2. Bin limit sizes for the FSSP-100 particle counter for water droplets (Mie calculations) and from hexagonal particles modelling for the refractive index of ice (1.31) assuming particles having a mean aspect ratio of 0.5. Results are reported for the nominal and extended size ranges.

\begin{tabular}{|c|c|c|c|c|c|c|c|c|c|}
\hline \multicolumn{10}{|c|}{ Nominal Range: $3-45 \mathrm{~mm}$} \\
\hline \multirow{2}{*}{$\begin{array}{l}\text { Channel } \\
\text { number }\end{array}$} & \multicolumn{3}{|c|}{ Water droplets (Mie) } & \multicolumn{3}{|c|}{ Rought Hexagonal ice particles } & \multicolumn{3}{|c|}{ Smooth Hexagonal ice particles } \\
\hline & $\min$ & median & $\max$ & $\min$ & median & $\max$ & $\min$ & median & $\max$ \\
\hline 1 & 1.5 & 3 & 4.5 & 2.3 & 3.6 & 4.8 & 1.5 & 3.5 & 5.8 \\
\hline 2 & 4.5 & 6 & 7.5 & 4.8 & 6.1 & 7.3 & 5.8 & 8.4 & 11.0 \\
\hline 3 & 7.5 & 9 & 10.5 & 7.3 & 8.5 & 9.8 & 11.0 & 13.9 & 16.8 \\
\hline 4 & 10.5 & 12 & 13.5 & 9.8 & 11.0 & 12.2 & 16.8 & 19.8 & 23.0 \\
\hline 5 & 13.5 & 15 & 16.5 & 12.2 & 13.5 & 14.7 & 23.0 & 26.2 & 29.5 \\
\hline 6 & 16.5 & 18 & 19.5 & 14.7 & 16.0 & 17.2 & 29.5 & 32.9 & 36.4 \\
\hline 7 & 19.5 & 21 & 22.5 & 17.2 & 18.4 & 19.7 & 36.4 & 39.9 & 43.5 \\
\hline 8 & 22.5 & 24 & 25.5 & 19.7 & 20.9 & 22.1 & 43.5 & 47.1 & 50.8 \\
\hline 9 & 25.5 & 27 & 28.5 & 22.1 & 23.4 & 24.6 & 50.8 & 54.5 & 58.4 \\
\hline 10 & 28.5 & 30 & 31.5 & 24.6 & 25.9 & 27.1 & 58.4 & 62.2 & 66.1 \\
\hline 11 & 31.5 & 33 & 34.5 & 27.1 & 28.3 & 29.6 & 66.1 & 70.1 & 74.0 \\
\hline 12 & 34.5 & 36 & 37.5 & 29.6 & 30.8 & 32.0 & 74.0 & 78.1 & 82.2 \\
\hline 13 & 37.5 & 39 & 40.5 & 32.0 & 33.3 & 34.5 & 82.2 & 86.3 & 90.4 \\
\hline 14 & 40.5 & 42 & 43.5 & 34.5 & 35.8 & 37.0 & 90.4 & 94.6 & 98.9 \\
\hline 15 & 43.5 & 45 & 46.5 & 37.0 & 38.2 & 39.5 & 98.9 & 103.1 & 107.4 \\
\hline \multicolumn{10}{|c|}{ Extended Range: 6-90 mm } \\
\hline & \multicolumn{3}{|c|}{ Water droplets (Mie) } & \multicolumn{3}{|c|}{ Hexagonal ice particles } & \multicolumn{3}{|c|}{ Smooth Hexagonal ice particles } \\
\hline $\begin{array}{c}\text { Channel } \\
\text { number }\end{array}$ & $\min$ & median & $\max$ & $\min$ & median & $\max$ & $\min$ & median & $\max$ \\
\hline 1 & 3 & 6 & 9 & 3.6 & 6.1 & 8.5 & 3.5 & 8.4 & 13.9 \\
\hline 2 & 9 & 12 & 15 & 8.5 & 11.0 & 13.5 & 13.9 & 19.8 & 26.2 \\
\hline 3 & 15 & 18 & 21 & 13.5 & 16.0 & 18.4 & 26.2 & 32.9 & 39.9 \\
\hline 4 & 21 & 24 & 27 & 18.4 & 20.9 & 23.4 & 39.9 & 47.1 & 54.5 \\
\hline 5 & 27 & 30 & 33 & 23.4 & 25.9 & 28.3 & 54.5 & 62.2 & 70.1 \\
\hline 6 & 33 & 36 & 39 & 28.3 & 30.8 & 33.3 & 70.1 & 78.1 & 86.3 \\
\hline 7 & 39 & 42 & 45 & 33.3 & 35.8 & 38.2 & 86.3 & 94.6 & 103.1 \\
\hline 8 & 45 & 48 & 51 & 38.2 & 40.7 & 43.2 & 103.1 & 111.8 & 120.5 \\
\hline 9 & 51 & 54 & 57 & 43.2 & 45.7 & 48.1 & 120.5 & 129.5 & 138.5 \\
\hline 10 & 57 & 60 & 63 & 48.1 & 50.6 & 53.1 & 138.5 & 147.6 & 156.9 \\
\hline 11 & 63 & 66 & 69 & 53.1 & 55.6 & 58.0 & 156.9 & 166.3 & 175.7 \\
\hline 12 & 69 & 72 & 75 & 58.0 & 60.5 & 63.0 & 175.7 & 185.3 & 195.0 \\
\hline 13 & 75 & 78 & 81 & 63.0 & 65.5 & 67.9 & 195.0 & 204.8 & 214.6 \\
\hline 14 & 81 & 84 & 87 & 67.9 & 70.4 & 72.9 & 214.6 & 224.6 & 234.6 \\
\hline 15 & 87 & 90 & 93 & 72.9 & 75.4 & 77.8 & 234.6 & 244.7 & 255.0 \\
\hline
\end{tabular}

and $35 \mu \mathrm{m}$, does not represent true size response but most likely corresponds to much bigger ice particles (i.e. $55 \mu \mathrm{m}-$ $86 \mu \mathrm{m})$ if we consider the calibration results above valid for smooth hexagonal particles. The smooth hexagonal particle model is probably not an adequate modeling of real crystals. Size results obtained from this hypothesis represent the upper limit of geometrical size. Real geometrical crystal sizes are probably between those calculated from this hypothesis and the spherical or rough model.
The examination of the Polar Nephelometer phase function and crystal images (Fig. 4) confirm quantitatively the presence of rough crystals rather than smooth crystals. Qualitatively however it is difficult to conclude as the PN phase function does not show peaks (halos...) characteristic of smooth particles. Sensitivity studies should be carried out in the future in this regard, but are beyond the scope of this paper. 


\subsection{Effects of ice crystals on FSSP measurements}

In order to assess the maximum effects of ice crystals on the FSSP derived parameters, the contribution on number concentration, extinction and liquid/ice water content of ice particles larger than $24 \mu \mathrm{m}$ has been evaluated assuming size calibration as reported on Table 2 . The corresponding values have been scaled by the values calculated over the full FSSP size range assuming water droplets for particles smaller than $24 \mu \mathrm{m}$ and smooth and rough ice particles for larger sizes.

The ratio values (DELTA parameter) are calculated as follows:

$$
\mathrm{DELTA}=100 * \mathrm{XI} /(\mathrm{XW}+\mathrm{XI})
$$

where: $\mathrm{XI}$ is the sum from FSSP channels 8 to 15 of $N i * A$, $\mathrm{XW}$ is the sum from FSSP channels 0 to 7 of $N i * A, N i$ the concentration of class $i$ and $A$ corresponds to the diameter, the surface or the volume of the particles.

The results are reported on Fig. 8a and b (rough) and c and $d$ (smooth) with DELTA (in \%) as a function of the REX extinction ratio (CPI data to PN measurements, see definition in Sect. 3.3) and the asymmetry parameter, respectively. The data were obtained for the four selected cloud sequences labelled a, b, c and d on Fig. 1.

In the rough condition, the volume parameter is affected the most by the contribution of ice particles. For REX values smaller than 0.2, DELTA is no larger than $25 \%, 10 \%$ and $5 \%$ for the volume, the surface and the concentration measurements, respectively. At the same time the asymmetry parameter remains within a deviation of 0.02 (Fig. 8b). In this case, the FSSP size distribution is not largely affected by the presence of ice crystals. When REX reaches about 0.4 with a corresponding $g$-decrease of $0.04(0.80)$ the effects of ice crystals become significant $(35 \%$ and $65 \%$ on the surface and volume, respectively). For larger REX values, ice crystals highly dominate the FSSP size distribution.

In the smooth condition, the behaviour described previously is also observed, with a greater deviation until the REX parameter rises above 0.1. For volume parameter, DELTA equals to $70 \%$ as soon as the presence of ice is detected.

This observation shows that complete interpretation of FSSP measurements in the presence of ice crystals (ice cloud or mixed cloud) is not possible without an appropriate consideration of scattered light by ice crystals. Probes such as the Polar Nephelometer provide crucial additional information for proper interpretation of all probes based on forward scattering light measurements (i.e. FSSP or CDP Probes).

\section{Origin of the second mode on the particle size distribution measured by the FSSP 100}

If we now consider the origins of the FSSP-100 second mode, two main questions arise:
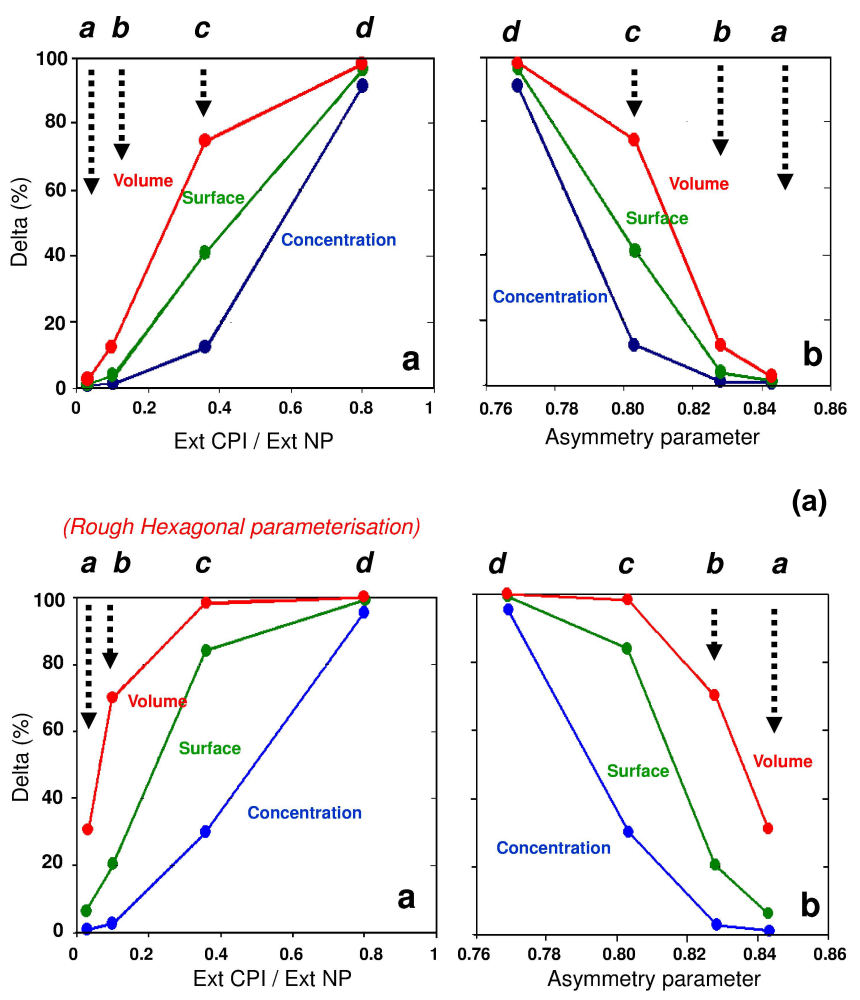

(Smooth Hexagonal parameterisation)

(b)

Fig. 8. Relative contribution of the ice particles (DELTA values) on number concentration, extinction (surface) and liquid/ice water content (volume) measurements as a function of: the REX extinction ratio (CPI data to PN measurements) and the asymmetry parameter, respectively. The data have been obtained during the cloud sequences labelled a, b, c and d (see Fig. 1). (a) Rough hexagonal crystals simulation. (b) Smooth hexagonal crystals simulation.

1. whether the deduced size of ice particles in the range $20-35 \mu \mathrm{m}$ is indeed real;

2. whether those particles are natural crystals or artefacts.

\subsection{On the particle sizing deduced from FSSP measurements}

A discussion of real sizes of crystals should be founded first of all on the principles of FSSP measurements. The FSSP sizes particles according to the energy scattered by a particle over the solid angle that is usually comprised between $3^{\circ}$ and $12^{\circ}$. In other words, the properties of phase functions at other scattering angles have no consequence. Moreover, the manufacturer's size calibration data are applicable to water droplets. Thus, an ice crystal size measured by the FSSP corresponds to the equivalent optical diameter of a water droplet.

Taking this into account, three effects can be explored in order to explain a possible underestimation or overestimation 
of the geometrical size deduced from the equivalent optical size.

Firstly, as largely discussed previously concerning the calibration curve of the FSSP, the equivalent optical size of a smooth ice crystal can be much larger compared to its geometrical size.

Secondly, air flow around the aircraft can induce turbulences near the probe (King, 1986). This author shows an example of the effect of turbulence on a preferential orientation of ice crystals.

The example described by King (1986) shows that plates can be viewed as columns with a $2 \mathrm{D}-\mathrm{C}$ probe. In this example, particle measurement size is smaller than geometrical size.

Concerning the air flow, two disturbances could be distinguished: (a) air flow around the aircraft, and, (b) air flow disturbance due to the probe itself.

In the case of the air flow around the aircraft, no particular disturbance may be noticed here. One reason is that the aircrafts used in this study were used during several cloud in situ measurement campaigns. The problem of particle orientation has never been noted from an examination of viewer probe images. All probes (FSSP and viewer) were mounted on wing pods at a distance from the leading edge calculated so as to be outside the flow perturbation.

Another reason, as shown on Fig. 6, is that bimodal FSSP PSD have been observed for three different campaigns where different aircraft were used: POLARCAT 2008 with an ATR42, ASTAR 2007 with a Do228 and AEROCONTRAIL with a Falcon20. In others words, we show cases for three different aircrafts with three different nominal airspeeds. For these three experiments, the analysis of 2-D images did not show any preferential orientation of crystals. It seems reasonable to extrapolate this observation to FSSP measurements by assuming that no preferential orientation was caused by flow around the aircraft.

The flow distortion around the PMS canister however (King, 1986; McPherson and Baumgardner, 1988) may explain the preferential orientation of ice crystals of two-dimensional regular shape structure (i.e. plates, stars, columns, ...). In mixed-phase clouds, ice crystal shapes are largely dominated by irregular patterns with 3-D-structure, mainly due to vapor deposition during the Wegener-Bergeron-Findeisen process (see examples of ice crystals in Fig. 4). Therefore the effects of a preferential orientation of such ice crystals are unlikely to be significant.

Thirdly, the second mode could possibly be caused by out of focus particles. Indeed in the FSSP optics, data processing should leads to the rejection of particles that are out of the depth of field (DOF). However, due to the complicated reflective and scattering properties of ice crystals, processing may accept aspherical particles that are out of the DOF (Gardiner and Hallett, 1985; Dye and Baumgardner, 1984). In this case, potentially accepted particles out of the DOF pass through the laser cross section in a larger, but less intense, portion of the beam. The geometrical size of the particle is therefore underestimated. This DOF is larger than the water droplet DOF and thus the concentration is overestimated.

This effect probably exists here. With our FSSP version, we have no extra recorded parameters to demonstrate the variability of the DOF as a function of particle types. Combining the increase in the DOF with the increase of the transit time of large ice crystals due to their shape, Gardiner and Hallett (1985) evaluated the overestimation of the concentration as being larger by a factor of about 30 . This factor does not satisfactorily explain the different orders of magnitude between the CPI measurement and the FSSP (see Fig. 4).

To resume, on the one hand, the second mode observed on the FSSP PSD may come from large undersized ice particles. This feature can be qualitatively explained by the scattering of smooth ice crystals as our modeling has shown and also by the DOF variability in the presence of ice crystals. But it is quantitatively not possible to demonstrate and explain with our set of data. A possible orientation effect due to air flow is rejected.

On the other hand, this bimodal feature may come from small oversized ice particles. To our knowledge, no available scattering model explains this feature. We draw attention however to the very small number of studies concerning the scattering of only one oriented ice crystal in regards to FSSP/CDP optics.

\subsection{On the reality of FSSP 100 second mode particles in terms of cloud physics}

In this study, we had no means of discriminating real and artefact ice particles related to the FSSP-100 second mode. Our FSSP version is not equipped to record of the particle interarrival times contrary to new probe versions i.e. Fast FSSP or Cloud Droplet Probe (CDP).

Nevertheless, we may wonder what cloud physics process is at the origin of this second mode. It may either be the result of frozen water droplets or else small ice crystals growing more rapidly than the droplets due to the WegenerBergeron-Findeisen (WBF) process. Because the data presented in this paper address a representative sample of measurements in mixed-phase clouds at different stages of evolution, the subsequent second mode of the size distribution should be observed on a broad size range, i.e. small diameters at the onset of the Wegener-Bergeron-Findeisen process (Fig. 4b for instance) and larger diameters at further cloud evolution (Fig. $4 \mathrm{~d}$ for instance). But our observations clearly show that the second mode is always found in a rather narrow size range $(25-35 \mu \mathrm{m})$. Moreover in cirrus clouds the Wegener-Bergeron-Findeisen process does not exist. The corresponding FSSP-100 cirrus measurements (see Fig. 6b) also show a second mode in a similar size range and confirm that the second mode of the size distribution is not a consequence of the WBF process. Thus, the presence of the second mode on the FSSP PSD in very different meteorological 


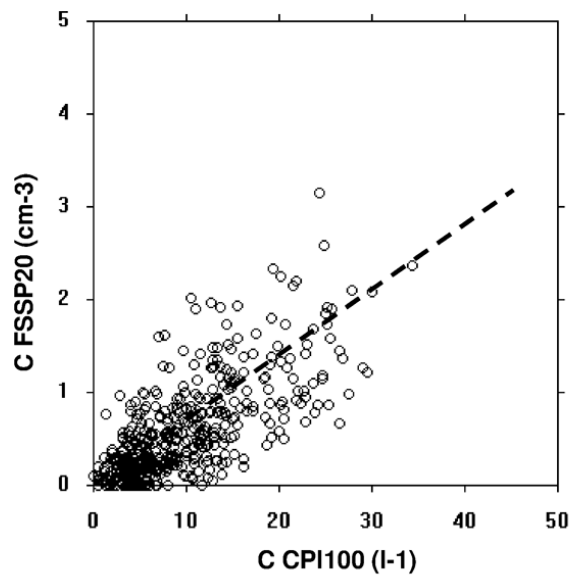

Fig. 9. Number concentration of ice crystals $(d>20 \mu \mathrm{m})$ measured by the FSSP-100 versus the concentration of ice particles $(d>100 \mu \mathrm{m})$ measured with the CPI (ASTAR, 8 April 2007).

situations is an argument for an artefact rather than a natural process like WBF.

Follows convincing results from measurements carried out using cloud probes with new arms and leading edge tips specially designed to reduce shattering effects (Korolev et al., 2011). The FSSP-100 second mode peaked in the range 25$35 \mu \mathrm{m}$ is likely to be caused by the shattering of large ice crystals on the probe tips. Figure 9 shows that the concentration of particles larger than $20 \mu \mathrm{m}$ (hypothesized to be ice shattered-fragments measured by the FSSP) is related to the concentration of (natural) ice particles larger than $100 \mu \mathrm{m}$ (CPI data). We note in passing that the data on Fig. 9 correspond to the sampling sequence of the lowermost cloud parts (from 10:58 to 11:06 UT, see Fig. 1) where only precipitating ice particles were observed. We propose below a very simple calculation in order to demonstrate the quasi certitude of the presence of ice shattering in our sample of mixed cloud.

Let us consider, for example, a cloud with a real ice crystal size-distribution as presented on the Fig. 10 with a MVD of $310 \mu \mathrm{m}$ and a total concentration of particles larger than $100 \mu \mathrm{m}$ of $20 \mathrm{1}^{-1}$. The impacting surface is evaluated by the surface of the leading edge of the FSSP sample tube on which the impacting ice crystals shatter and disperse. Considering outer and inner diameters of $4.5 \mathrm{~cm}$ and $3.8 \mathrm{~cm}$, respectively, the impinging surface is $4.5 \mathrm{~cm}^{2}$ and the corresponding swept volume is $45 \mathrm{~s} \mathrm{~s}^{-1}$ for an airspeed of $100 \mathrm{~m} \mathrm{~s}^{-1}$. The rate of impacting ice crystals larger than $100 \mu \mathrm{m}$ is therefore estimated at $900 \mathrm{~s}^{-1}$ considering the concentration of ice particles $(d>100 \mu \mathrm{m})$ of $201^{-1}$. This value increases by a magnitude of 1 to 2 if we include ice crystals smaller than $100 \mu \mathrm{m}$. Vidaurre and Hallett (2009, see their Fig. 6) using Cloudscope replicator data at $130 \mathrm{~m} \mathrm{~s}^{-1}$ show a number of fragments resulting from the breakup of ice particles. This number ranges from a few units to 1000 as a function of diameter.

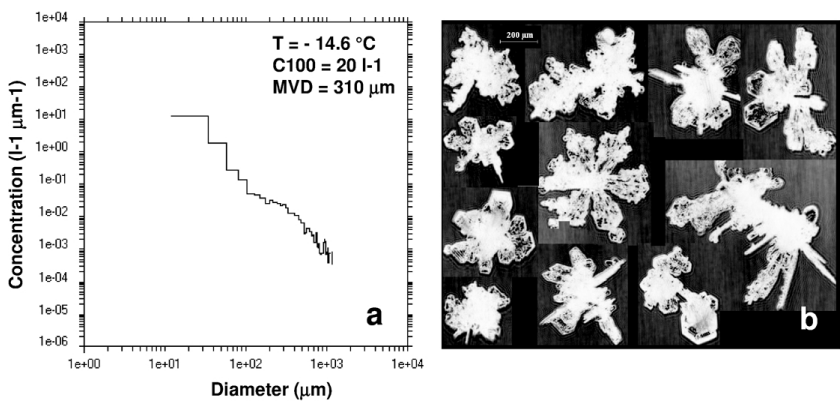

Fig. 10. (a) Particle size distribution measured by the CPI during the sequence between 10:58 and 11:06 UTC on Fig. $1\left(T=-14.6^{\circ} \mathrm{C}\right)$. (b): Examples of ice crystal images measured by the CPI during this sequence.

The number of impacting ice particles multiplied by the number of generated fragments can lead to values with roughly the same concentration measured by the FSSP in the second mode of FSSP PSD.

This very simple evaluation may be sufficient in order to conclude that the ice crystal shattering effect is the main cause of ice crystals observed by FSSP.

There are still heated debates about the magnitude of the contribution of small ice crystals to the concentration and bulk microphysical parameters. Korolev and Isaac (2005), Lawson et al. (2006) and Protat et al. (2010) suggest that small ice crystals do significantly contribute to bulk microphysical properties. In relatively extreme situations, Heymsfield (2007) shows that shattering effects could add about $15 \%$ to the ice water content from the FSSP, while the problem is even greater for extinction and number concentration. Field et al. (2003) and McFarquhar et al. (2007) confirm that shrouded inlets may cause particle shattering with a subsequent enhancement of the total concentration of ice crystals, especially at $D<50 \mu \mathrm{m}$. Korolev et al. (2011) found that ice crystal concentrations could be increased by up to 2 orders of magnitude due to the impact of crystals with the sample tube of the FSSP. These considerations agree with our estimation.

\section{Conclusions}

In this paper we have analyzed cloud in situ measurements performed in boundary layer clouds during ASTAR2007 and POLARCAT experiments. We show that in mixed phase clouds FSSP measurements could be misinterpreted, resulting from ice crystal artefacts or improper measurement of natural ice crystals. The presence of ice crystals leads to a bimodal feature of the particle size distribution and considerably affects accuracy on derived parameters. The combined measurements of the FSSP and the Polar Nephelometer give a coherent description of the effect of the ice crystals on the FSSP response. The FSSP particle size distributions are characterized by a bimodal shape with a second mode peaked 
between 25 and $35 \mu \mathrm{m}$, related to ice crystals. The larger the amplitude of the second mode, the greater the ratio (REX) of extinction brought by ice particles to the total extinction (water droplets and ice crystals). The differences between the measured and theoretical (FSSP-100) phase functions at sideward scattering angles increase with REX values. This feature undoubtedly reveals the occurrence of aspherical ice particles. These observations have been extended to the combined data sets in mixed-phase clouds from ASTAR 2007 and POLARCAT experiments. A similar feature is observed with the FSSP-100 at airspeed up to $200 \mathrm{~m} \mathrm{~s}^{-1}$ and with the FSSP300 series.

One sensitive aspect that could be considered is the probe size response to aspherical particles. In order to assess the size calibration for clouds of ice crystals the response of the FSSP-100 probe has been numerically simulated using a light scattering model of randomly oriented hexagonal ice particles and assuming both smooth and rough crystal surfaces. The results suggest that the second mode, peaked between $25 \mu \mathrm{m}$ and $35 \mu \mathrm{m}$, does not represent true geometrical size but an equivalent optical size for a water droplet, smaller than the geometrical size. This underestimation becomes extremely large if smooth crystal surfaces are considered. In our documented situation, measured Polar Nephelometer phase function suggests the presence of rough crystals. Nevertheless, a sensitivity study would need to be done to conclude quantitatively. There are no means of discriminating real and artefact ice particles related to the FSSP-100 secondary mode without additional data such as interarrival time that is not commonly available, and even then results may not be conclusive. However a literal interpretation of the cloud in situ measurements suggests that the FSSP-100 secondary mode peaked in the range $25-35 \mu \mathrm{m}$ is likely to be due to the shattering of large ice crystals on the probe inlet.

Acknowledgements. This work was funded by the Centre National d'Etudes Spatiales (CNES), the Institut Polaire Français Paul Emile Victor (IPEV), the Institut National des Sciences de l'Univers (INSU/CNRS) and the German Research Foundation (DFG, WE 1900/8-1). We thank the members of OPTIMARE GmbH, DLR (Deutsches Zentrum für Luft- und Raumfahrt) and Service des Avions Français Instrumentés pour la Recherche en Environnement (SAFIRE) who organize the experiment managements and aircraft operations. The ECMWF center is acknowledged for the reliable access to the forecasts and analysis. We acknowledge A. Herber (AWI), J. Pelon, K. Law (LATMOS), A. Schwarzenboeck and J.F. Fournol (LaMP) for their active participation to the experiment. The authors are grateful to P. Yang for providing the IGOM code. The authors are grateful to D. Baumgardner and the anonymous reviewer for important comments that strengthened the manuscript. We acknowledge K. James who reviewed the manuscript.

Edited by: M. Krämer

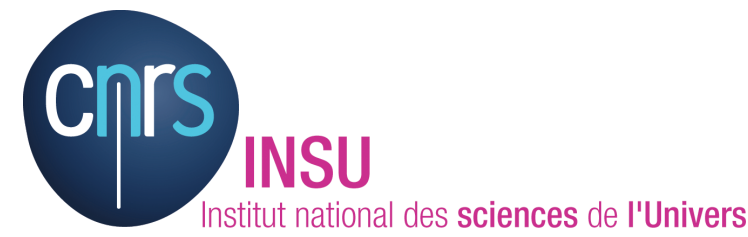

The publication of this article is financed by CNRS-INSU.

\section{References}

Ashenden, R. and Marwitz, J. D.: Characterizing the supercooled large droplet environment with corresponding turboprop aircraft response, J. Aircraft, 35, 912-920, 1998.

Baumgardner, D., Dye, J. E., Gandrud, B. W., and Knollenberg, R. G.: Interpretation of measurements made by the Forward Scattering Spectrometer Probe (FSSP-300) during the Airborne Arctic Stratospheric Expedition, J. Geophys. Res., 97, 8035-8046, 1992.

Baumgardner, D., Gayet, J.-F., Gerber, H., Korolev, A. V., and Twohy, C.: Clouds/Measurement Techniques In Situ, in: Encyclopedia of Atmospheric Sciences, edited by: Holton, J. R., Curry, J. A., and Pyle, J., Academic Press, London, 4000 pp., 2002.

Baumgardner, D., Brenguier, J. L., Bucholtz, A., Coe, H., DeMott, P., Garrett, T. J., Gayet, J. F., Hermann, M., Heymsfield, A., Korolev, A., Krämer, M., Petzold, A., Strapp, W., Pilewskie, P., Taylor, J., Twohy, C., Wendisch, M., Bachalo, W., and Chuang, P.: Airborne instruments to measure atmospheric aerosol particles, clouds and radiation: A cook's tour of mature and emerging technology, Atmos. Res., 102, 10-29, doi:10.1016/j.atmosres.2011.06.021, 2011.

Borrmann, S., Luo, B., and Mishchenko, M.: Application of the T-matrix method to the measurement of aspherical (ellipsoidal) particles with forward scattering optical particle counters, J. Aerosol Sci., 31, 789-799, 2000.

Cober, S. G. and Isaac, G. A.: Characterization of Aircraft Icing Environments with Supercooled Large Drops for Application to Commercial Aircraft Certification, J. Appl. Meteorol. Climatol., 51, 265-284, 2012.

Cober, S. G., Isaac, G. A., and Strapp, J. W.: Aircraft icing measurements in east coast winter storms, J. Appl. Meteor., 34, 88-100, 1995.

Cober, S. G., Korolev, A. V., Strapp, J. W., and Marcotte, D. L.: Measurements of aircraft icing environments which include supercooled large drops, 37th Aerospace Sci. Meeting, Reno, NV, AIAA Paper 99-0494, 1999.

Cober, S. G., Isaac, G. A., Korolev, A. V., and Strapp, J. W.: Assessing Cloud-Phase Conditions, J. Appl. Meteor., 40, 1967-1983, 2001.

Crépel, O., Gayet, J.-F., Fournol, J.-F., and Oshchepkov, S.: A new airborne Polar Nephelometer for the measurement of optical and microphysical cloud properties. Part II: Preliminary tests, Ann. Geophys., 15, 460-470, doi:10.1007/s00585-997-0460-0, 1997.

Dye, J. E. and Baumgardner, D.: Evaluation of the Forward Scattering Spectrometer Probe, Part I: Electronic and Optical Studies, J. Atmos. Ocean. Technol., 4, 329-344, 1984.

Engvall, A.-C., Krejci, R., Ström, J., Treffeisen, R., Scheele, R., Hermansen, O., and Paatero, J.: Changes in aerosol properties 
during spring-summer period in the Arctic troposphere, Atmos. Chem. Phys., 8, 445-462, doi:10.5194/acp-8-445-2008, 2008.

Field, P. R., Wood, R., Brown, P. R. A., Kaye, P. H., Hirst, E., Greenaway, R., and Smith, J. A.: Ice particle interarrival times measured with a Fast FSSP, J. Atmos. Sci., 20, 249-261, 2003.

Field, P. R., Heymsfield, A. J., and Bansemer, A.: Shattering and interarrival times measured by optical array probes in ice clouds, J. Atmos. Ocean. Tech., 23, 1357-1371, 2006.

Fugal, J. P. and Shaw, R. A.: Cloud particle size distributions measured with an airborne digital in-line holographic instrument, Atmos. Meas. Tech., 2, 259-271, doi:10.5194/amt-2-259-2009, 2009.

Gardiner, B. A. and Hallett, J.: Degradation of In-Cloud Forward Scattering Spectrometer Probe Measurements in the Presence of Ice Particles, J. Atmos. Ocean. Tech., 2, 171-180, 1985.

Garrett, T. J., Hobbs, P. V., and Gerber, H.: Shortwave, singlescattering properties of arctic ice clouds, J. Geophys. Res., 106, 15155-15172, 2001.

Gayet, J.-F., Febvre, G., and Larsen, H.: On the reliability of the PMS FSSP probe in the presence of small ice crystals, J. Atmos. Ocean. Tech., 13, 1300-1310, 1996.

Gayet, J. F., Crépel, O., Fournol, J. F., and Oshchepkov, S.: A new airborne polar Nephelometer for the measurements of optical and microphysical cloud properties. Part I: Theoretical design, Ann. Geophys., 15, 451-459, doi:10.1007/s00585-997-0451-1, 1997.

Gayet, J.-F., Auriol, F., Oshchepkov, S., Schröder, F., Duroure, C., Febvre, G., Fournol, J.-F., Crépel, O., Personne, P., and Daugeron, D.: In situ measurements of the scattering phase function of stratocumulus, contrails and cirrus, Geophys. Res. Lett., 25, 971-974, 1998.

Gayet, J.-F., Asano, S., Yamazaki, A., Uchiyama, A., Sinyuk, A., Jourdan, O., and Auriol, F.: Two case studies of continental-type water and maritime mixed-phased stratocumuli over the sea. Part I : Microphysical and Optical propertie, J. Geophys. Res., 107, D21, doi:10.1029/2001JD001106, 2002.

Gayet, J.-F., Mioche, G., Dörnbrack, A., Ehrlich, A., Lampert, A., and Wendisch, M.: Microphysical and optical properties of Arctic mixed-phase clouds. The 9 April 2007 case study., Atmos. Chem. Phys., 9, 6581-6595, doi:10.5194/acp-9-6581-2009, 2009.

Gayet, J.-F., Shcherbakov, V., Voigt, C., Schumann, U., Schäuble, D., Jessberger, P., Petzold, A., Minikin, A., Schlager, H., Dubovik, O., and Lapyonok, T.: The evolution of microphysical and optical properties of an A380 contrail in the vortex phase, Atmos. Chem. Phys., 12, 6629-6643, doi:10.5194/acp-12-66292012, 2012.

Heymsfield, A. J.: On measurements of small ice particles in clouds, Geophys. Res. Lett., 34, L23812, doi:10.1029/2007GL030951, 2007.

Ivanova, D. C., Mitchell, D. L., Arnott, W. P., and Poellot, M.: A GCM parameterization for bimodal size spectra and ice mass removal rates in mid-latitude cirrus clouds, Atmos. Res., 59, 89113, 2001.

Ivanova, D. C., Mitchell, D. L., and McFarquhar, G. M.: A trimodal Size Distribution Parametrization for tropical Cirrus Clouds, Fourteenth ARM Science Team Meeting Proceedings, Albuquerque, New Mexico, 22-26 March, 2004.

Jensen, E. J., Lawson, P., Baker, B., Pilson, B., Mo, Q., Heymsfield, A. J., Bansemer, A., Bui, T. P., McGill, M., Hlavka, D.,
Heymsfield, G., Platnick, S., Arnold, G. T., and Tanelli, S.: On the importance of small ice crystals in tropical anvil cirrus, Atmos. Chem. Phys., 9, 5519-5537, doi:10.5194/acp-9-5519-2009, 2009.

Jourdan, O., Mioche, G., Garret, T. J., Schwarzenbock, A., Vidot, J., Xie, Y., Shcherbakov, V., Duroure, C., Yang, P., and Gayet, J.-F.: Coupling of the microphysical and optical properties of arctic clouds during the ASTAR 2004 experiment: Implications for light scattering modelling, J. Geophys. Res., 115, D23206, doi:10.1029/2010JD014016, 2010.

King, W. D.: Air Flow and Particle Trajectories around Aircraft Fuselages. IV: Orientation of Ice Crystals, J. Atmos. Ocean. Technol., 3, 433-439, 1986.

Knollenberg, R. G.: The optical array: An alternative to scattering or extinction for airborne particle size determination, J. Appl. Meteor., 9, 86-103, 1970.

Knollenberg, R. G.: Techniques for probing cloud microstructure, Clouds: Their formation, optical properties and effects, edited by: Hobbs, P. V. and Deepak, A., Academic Press, 495. pp., 1981.

Korolev, A. V. and Isaac, G. A.: Shattering during sampling by OAPs and HVPS, Part I: Snow particles, J. Atmos. Ocean. Tech., 22, 528-543, 2005.

Korolev, A., Isaac, G. A., Cober, S. G., Strapp, J. W., and Hallett, J.: Microphysical charaterisation of mixed-phase clouds, Q. J. R. Meteorol. Soc., 129, 39-65, 2003.

Korolev, A., Emery, E., Strapp, W., Cober, S., Isaac, G., Wasey, M., and Cober, S. G.: Small ice particles in tropospheric clouds: fact or artifact?, Airborne Icing Instrumentation Evaluation Experiment, B. Am. Meteorol. Soc., 92, 967-973, doi:10.1175/2010BAMS3141.1, 2011.

Law, K. S., Ancellet, G., Pelon, J., Turquety, S., Clerbaux, C., Pommier, M., de Villiers, R., Gayet, J.-F., Schwarzeboeck, A., Nedelec, P., Schneider, J., and Borrmann, S., 2008 : POLARCATFrance Airborne Experiment: first results, Intern. Global Atmospheric Chemistry conference (IGAC), Annecy, France, 7-12 September, 2008.

Lawson, R. P.: Effects of ice particles shattering on the 2D-S probe, Atmos. Meas. Tech., 4, 1361-1381, doi:10.5194/amt-4-13612011, 2011.

Lawson, R. P., Baker, B. A., and Schmitt, C. G.: An overview of microphysical properties of Arctic clouds observed in May and July 1998 during FIRE ACE, J. Geophys. Res., 106, 14989-15014, 2001.

Lawson, R. P., O'Connor, D., Zmarzly, P., Weaver, K., Baker, B. A., Mo, Q., and Jonsson, H.: The 2D-S (Stereo) probe: Design and preliminary tests of a new airborne, high-speed, highresolution imaging probe, J. Atmos. Ocean. Technol., 23, 14621477, doi:10.1175/JTECH1927.1, 2006.

MacPherson, J. I. and Baumgardner, D.: Airflow about King Air Wingtip-Mounted Cloud Particle Measurement Probes, J. Atmos. Ocean. Technol., 5, 259-273, 1988.

McFarquhar, G., Zhang, G., Poellot, M. R., Kok, G. L., McCoy, R., Tooman, T., Fridlind, A., and Heymsfield, A.: Ice properties of single-layer stratocumulus during the Mixed-Phase Arctic Cloud Experiment, J. Geophys. Res., 112, D24201, doi:10.1029/2007JD008633, 2007.

Miller, D., Ratvasky, T., Bernstein, B., McDonough, F., and Strapp, J. W.: NASA/FAA/NCAR supercooled large droplet icing flight research: Summary of winter 96-97 flight operations, AIAA 36th 
Aerospace Sci. Meeting and Exhibit, Reno, NV, AIAA Paper 980577, 1998.

Mishchenko, M. I., Travis, L. D., Kahn, R. A., and West, R. A.: Modeling phase functions for dustlike tropospheric aerosols using a shape mixture of randomly oriented polydisperse spheroids, J. Geophys. Res., 102, 16831-16847, 1997.

Mitchell, D. L., Arnott, W. P., Schmitt, C., Lowenthal, D., and Edwards, J. M.: A fundamental difference between ice crystal and cloud droplet absorption: photon tunneling effects, 10th Conference on Atmospheric Radiation: A Symposium with Tributes to the Works of Verner E. Suomi, AMS, Madison, WI, 28 June-2 July 1999.

Nagel, D., Maixner, U., Strapp, W., and Wasey, M.: Advancements in Techniques for Calibration and Characterization of In Situ Optical Particle Measuring Probes, and Applications to the FSSP100 Probe, J. Atmos. Ocean Tech., 24, 745-760, 2007.

Niu, J., Carey, L. D., Yang, P., Vonder Haar, T. H.: Optical properties of a vertically inhomogeneous mid-latitude mid-level mixedphase altocumulus in the infrared region, Atmos. Res., 88, 234 242, 2008

Pinnick, R. G., Garvey, D. M., and Duncan, L. D.: Calibration of Knollenberg FSSP Light-Scattering Counters for Measurement of Cloud Droplets, J. Appl. Meteor., 20, 1049-1057, 1981.

Protat, A., McFarquhar, G., Um, J., and Delanoë, J.: Obtaining best estimates for the microphysical and radiative properties of tropical ice clouds from TWP-ICE in-situ microphysical observations, J. Appl. Meteor. Clim., 50, 895-915, doi:10.1175/2010JAMC2401.1, 2010.
Riley, J. T.: Mixed-phase icing conditions: A review. Airport and Aircraft Safety Research and Development Rep. DOT/ FAA/AR98/76, Federal Aviation Administration, Atlantic City, NJ, 45 pp., 1998.

Sassen, K. and Liou, K. N.: Scattering and polarized laser light by water droplets, mixed- phase and ice crystal clouds, Part I: Angular scattering patterns, J. Atmos. Sci., 36, 838-851, 1979.

Shcherbakov, V., Gayet, J.-F., Jourdan, O., Ström, J., and Minikin, A.: Light scattering by single ice crystals of cirrus clouds, Geophys. Res. Lett., 33, L15809, doi:10.1029/2006GL026055, 2006.

Shcherbakov, V., Gayet, J.-F., Febvre, G., Heymsfield, A. J., and Mioche, G.: Probabilistic model of shattering effect on in-cloud measurements, Atmos. Chem. Phys. Discuss., 10, 11009-11045, doi:10.5194/acpd-10-11009-2010, 2010.

Vidaurre, G. and Hallett, J.: Particle Impact and Breakup in Aircraft Measurement, J. Atmos. Ocean Tech., 26, 972-983, doi:10.1175/2008JTECHA1147.1, 2009.

Warren, S. G. and Brandt, R. E.: Optical constants of ice from the ultraviolet to the microwave: A revised compilation, J. Geophys. Res., 113, D14220, doi:10.1029/2007JD009744, 2008.

Yang, P. and Liou, K. N.: Geometric-optics-integral-equation method for light scattering by nonspherical ice crystals, Appl. Opt., 35, 6568-6584, 1996.

Yang, P. and Liou, K. N.: Single-scattering properties of complex ice crystals in terrestrial atmosphere, Contrib. Atmos. Phys., 71, 223-248, 1998.

Zhang, Z., Yang, P., Kattawar, G. W., and Wiscombe, W. J.: Singlescattering properties of Platonic solids in geometrical-optics regime, J. Q. S. R. Trans., 106, 595-603, 2007. 